Jurnal Informatika dan Rekayasa Perangkat Lunak (JATIKA)
Vol. 2, No.3, September 2021, page-page. 399 406
ISSN 2723-3367
E-ISSN 2797-3492
available online at:http://jim.teknokrat.ac.id/index.php/informatika

\title{
ANALISIS DAN PERANCANGAN KAMUS BAHASA ILMIAH TUMBUHAN BERBASIS ANDROID
}

\author{
Joni Alfian', Yuri Rahmanto ${ }^{2}$ \\ Universitas Teknokrat Indonesia ${ }^{1,2}$ \\ joni_alfian@teknokrat.ac.id
}

Published: 30 September 2021

\begin{abstract}
The scientific name of living things, especially plants, is one of the things that is basically very interesting to learn and know, because the scientific name of living things provides an important role, among others with scientific names it will easily know the characteristics, relationships of relatives, and interactions of living things in the environment. Knowledge of plant classification has generally been taught to high school students and MIPA students or biology majors, but interest in learning about plant taxonomy is still low due to the source of information that is not yet widely available. Therefore, the development of learning media is needed one of them by building an android-based plant scientific language dictionary application that can be one of the alternative learning media for students and students. The algorithm applied is sequential search that performs search faster because the search process is already in order. That way the interest in learning students and students about the scientific language of plants can be encouraged by the spirit in learning by using this learning medium. Based on the research that has been done, the application of the scientific language dictionary of plants can be used by students, students and the public as a means of learning in understanding the scientific names on each plant that is equipped with the alphabetic menu $a-z$ and plant categories and search features to make it easier for users to find plant names.
\end{abstract}

Keywords: Scientific Language Dictionary, Plant Dictionary, Sequential Search, Android

\begin{abstract}
Abstrak
Nama ilmiah dari makhluk hidup terutama tumbuhan merupakan salah satu hal yang pada dasarnya sangat menarik untuk dipelajari dan diketahui, karena nama ilmiah makhluk hidup memberikan peran penting, antara lain dengan nama ilmiah maka akan dengan mudah mengetahui ciri-ciri, hubungan kerabat, dan interaksi makhluk hidup di lingkungan. Pengetahuan tentang klasifikasi tumbuhan umumnya telah diajarkan pada siswa SMA dan mahasiswa MIPA atau jurusan biologi, akan tetapi minat untuk mempelajari tentang taksonomi dunia tumbuhan masih rendah dikarenakan sumber informasi yang belum tersedia secara luas. Oleh karena itu diperlukan pengembangan media pembelajaran salah satunya dengan membangun aplikasi kamus bahasa ilmiah tumbuhan berbasis android yang dapat menjadi salah satu media pembelajaran alternatif untuk siswa dan mahasiswa. Algoritma yang diterapkan yaitu sequential search yang melakukan pencarian lebih cepat karena proses pencarian sudah dalam terurut. Dengan begitu minat belajar siswa dan mahasiswa tentang bahasa ilmiah tumbuhan dapat terpacu semangatnya dalam belajar dengan menggunakan media pembelajaran ini. Berdasarkan penelitian yang telah dilakukan maka aplikasi kamus bahasa ilmiah tumbuhan ini dapat digunakan oleh siswa, mahasiswa dan masyarakat sebagai sarana belajar dalam memahami nama-nama ilmiah pada setiap tumbuhan yang dilengkapi menu abjad a-z dan kategori tumbuhan serta fitur pencarian untuk memudahkan pengguna dalam menemukan nama tumbuhan.
\end{abstract}

Kata Kunci: Kamus Bahasa Ilmiah, Kamus Tumbuhan, Sequential Search, Android

To cite this article:

Joni Alfian, Yuri Rahmanto. (2021). KAMUS BAHASA ILMIAH TUMBUHAN MENGGUNAKAN METODE SEQUENTIAL SEARCH BERBASIS ANDROID. Jurnal Informatika dan Rekayasa Perangkat Lunak, Vol(2) No(3), 399-406. 


\section{PENDAHULUAN}

Secara global penggunaan telepon seluler semakin meningkat secara pesat dalam beberapa tahun terakhir, jika dilakukan perbandingan antara pengguna PC dan perangkat mobile, perangkat mobile memiliki sekitar 3,5 kali pengguna lebih banyak dari perangkat PC, Selain perkembangan dibidang hardware, sistem operasi yang digunakan untuk perangkat seluler juga mengalami kemajuan yang pesat (Kurniawan et al., 2020; Nurmanto \& Gunawan, 2020; Shodik et al., 2019), salah satu sistem operasi yang populer saat ini adalah android yang merupakan salah satu sistem operasi open source berbasis kernel linux menggunakan mesin virtual yang dinamakan Dalvik, sistem operasi ini dikeluarkan oleh google pada tahun 2007. Ukuran yang kecil dan fungsi yang memudahkan komunikasi dan pengaksesan data merupakan salah satu sebab menariknya dunia mobile untuk terus dieksplorasi dan dikembangkan, termasuk untuk kepentingan edukasi yang bersifat ubiquitous dimana saja dan kapan saja.

Kebutuhan masyarakat terhadap layanan teknologi berbasis IT sangat bervariatif, salah satu kebutuhan adalah kebutuhan akan ketersediaan kamus dengan berbagai kepentingan mulai dari kamus yang bersifat umum seperti kamus bahasa hingga kamus istilah-istilah khusus seperti kamus politik, kamus ekonomi, kamus psikologi dan sebagainya (Rahmanto et al., 2021). Kamus yaitu buku acuan yang memuat kata dan ungkapan yang biasanya disusun menurut abjad berikut keterangan tentang maknanya dan berfungsi untuk membantu seseorang mengenal perkataan baru. Kamus istilah termasuk kategori kamus khusus karena merujuk pada kamus yang mempunyai fungsi khusus dan berisi istilah-istilah khusus dalam bidang tertantu, fungsinya untuk kegunaan ilmu

Kerajaan tumbuhan (Kingdom Plantae) merupakan satu kelompok besar dari semua jenis tumbuhan, setiap tumbuhan memiliki ciri-ciri fisiologis yang dapat digunakan untuk mengelompokkan jenis-jenis tumbuhan kedalam tingkatan yang lebih kecil atau disebut taksonomi tumbuhan, karena banyak jenis tumbuhan yang tumbuh maka akan sulit untuk mengetahui nama ilmiah dari setiap tumbuhan.

Nama ilmiah dari makhluk hidup terutama tumbuhan merupakan salah satu hal yang pada dasarnya sangat menarik untuk dipelajari dan diketahui, karena nama ilmiah makhluk hidup memberikan peran penting, antara lain dengan nama ilmiah maka akan dengan mudah mengetahui ciri-ciri, hubungan kerabat, dan interaksi makhluk hidup di lingkungan. Bahasa Latin atau bahasa ilmiah adalah sebuah bahasa Italik yang berasal dari Latium, sebuah daerah di Italia sekeliling kota Roma yang termasuk dalam rumpun Indo Eropa. Bahasa ini menjadi penting karena munculnya kekaisaran Romawi dimana bahasa Latin adalah bahasa resminya. Setelah runtuhnya kekaisaran Romawi, sekitar akhir abad ke-5, bahasa Latin tidak ikut runtuh melainkan semakin berkembang. Bahasa ini dipakai sebagai lingua franca, bahasa liturgis gereja dan bahasa ilmu pengetahuan, bahkan juga daerah-daerah yang tidak pernah ditaklukkan oleh Roma.

Pengetahuan tentang klasifikasi tumbuhan umumnya telah diajarkan pada siswa SMA dan mahasiswa MIPA atau jurusan biologi, akan tetapi minat untuk mempelajari tentang taksonomi dunia tumbuhan masih rendah dikarenakan sumber informasi yang belum tersedia secara luas, sedangkan bagi siswa dan mahasiswa nama ilmiah tumbuhan terdengar asing. Berdasarkan uraian diatas, penulis ingin membangun aplikasi kamus bahasa ilmiah tumbuhan.

Di dalam penelitian ini, penulis menggunakan penelitian sebelumnya yang dipakai sebagai acuan dan referensi penulis untuk memudahkan penulis dalam membuat penelitian ini. Menurut Sembiring (2013) dalam penelitiannya membuat Aplikasi Kamus mengatakan bahwa pencarian dibutuhkan algoritma atau metode yang efektif, karena proses pencarian merupakan salah satu bagian yang penting dalam pemprosesan data. Algoritma atau metode yang diterapkan yaitu Sequential Search yang melakukan pencarian lebih cepat karena proses pencarian sudah dalam terurut. Sequential Search sangat cocok digunakan dalam aplikasi kamus bahasa Indonesia Karo karena dapat menerjemahkan kata yang dicari dengan cepat, apabila kata yang dicari tidak ditemukan maka akan berakhir. Hasil dari penelitian ini berupa Aplikasi Kamus Bahasa Indonesia Karo berbasis web dapat menerjemahkan kata dengan cepat.

Tujuan utama yang mendasari pembuatan aplikasi kamus bahasa ilmiah tumbuhan ini adalah untuk menerapakan metode sequential search dan memberikan alternatif alat bantu bagi siswa, mahasiswa maupun masyarakat umum dalam memahami dan mempelajari klasifikasi dan tata nama ilmiah pada tumbuhan, sehingga tidak akan terjadi lagi kesalahan dalam penulisan klasifikasi dan tata nama ilmiah pada tumbuhan serta dapat digunakan dan dibawa keamanapun karena berupa software atau aplikasi dan diterapkan dalam perangkat Android sehingga lebih efisien dalam penggunaannya (Ahdan \& Setiawansyah, 2020, 2021).

Bahasa latin atau ilmiah adalah sebuah bahasa Italik yang berasal dari Latium, sebuah daerah di Italia sekeliling kota Roma yang termasuk dalam rumpun Indo Eropa. Bahasa ini menjadi penting karena munculnya kekaisaran Romawi dimana bahasa latin adalah bahasa resminya. Pada puncak kejayaan kerajaan ini, bahasa latin 
dituturkan dari pulau Britania di barat laut sampai Palestina di ujung tenggara dengan kata lain menjadi bahasa Internasional. Setelah runtuhnya kekaisaran Romawi, sekitar akhir abad ke-5, bahasa latin tidak ikut runtuh melainkan semakin berkembang. Bahasa ini dipakai sebagai lingua franca, bahasa liturgis gereja dan bahasa ilmu pengetahuan, bahkan juga daerah-daerah yang tidak pernah ditaklukan oleh Roma. Bahasa latin juga mempunyai turunan yang disebut sebagai sermo vulgaris (bahasa Roman/bahasa latin rakyat) yang dituturkan oleh antara lain bala tentara Romawi menjadi pengantar di seluruh daerah kerajaan. Di beberapa tempat bahasa ini bahkan menggantikan bahasa setempat. Bahkan bahasa Inggris pun sebagian besar diambil dari bahasa latin ini (selain bahasa Yunani Kuno tentunya).

\section{METODE PENELITIAN}

\section{Kerangka Penelitian}

Kerangka pemikiran merupakan hubungan antara konsep-konsep yang ingin diamati atau diukur melalui penelitian yang akan dilakukan (Megawaty et al., 2021; Setiawansyah et al., 2021; Sulistiani et al., 2021).

Berikut merupakan kerangka penelitian yang dilakukan pada gambar 1.

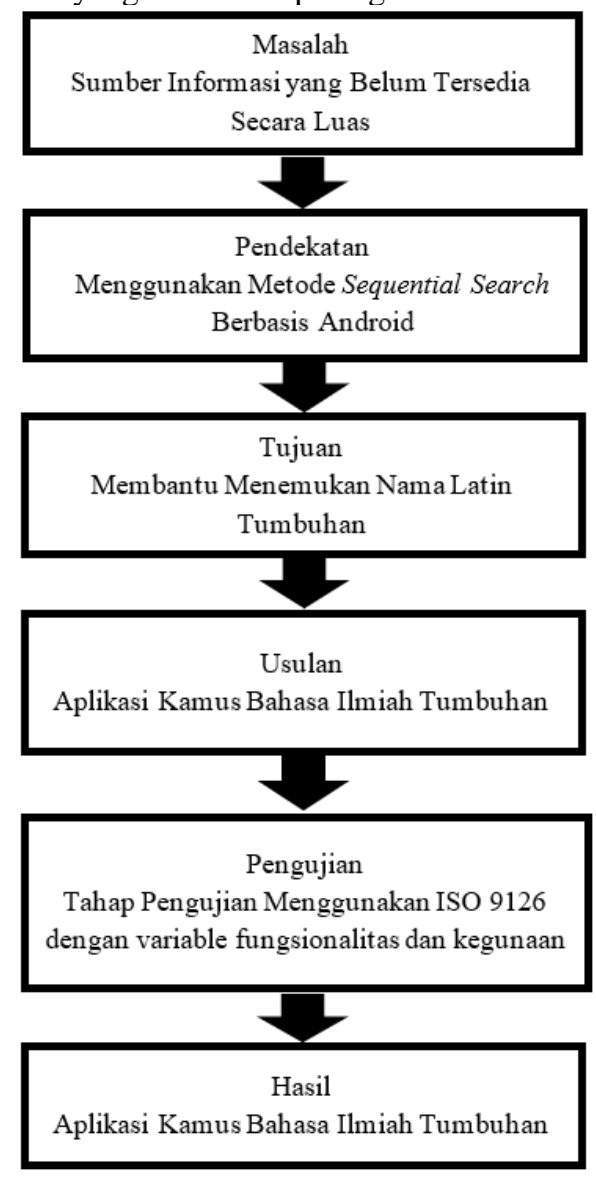

Keterangan :

Gambar 3.1 Kerangka Penelitian

a. Masalah

Tahapan penelitian ini diawali dengan penentuan masalah penelitian, yaitu kurangnya minat masyarakat umum untuk mempelajari tentang taksonomi dunia tumbuhan masih rendah dikarenakan sumber informasi yang belum tersedia secara luas.

b. Pendekatan

Pendekatan yang dimaksud adalah cara penulis untuk melakukan pendekatan terhadap metode yang akan digunakan. Dalam penelitian ini metode yang digunakan adalah Sequential Search berbasis android.

c. Tujuan

Tujuan dalam penelitian ini adalah untuk menerapakan metode sequential search dan memberikan alternatif 
alat bantu bagi siswa, mahasiswa maupun masyarakat umum dalam memahami dan mempelajari klasifikasi dan tata nama ilmiah pada tumbuhan.

d. Usulan

Usulan yang diajukan dalam tahapan penelitian ini adalah membangun sebuah aplikasi berupa kamus bahasa ilmiah tumbuhan berbasis android menggunakan metode sequential search.

e. Pengujian

Pengujian dilakukan dengan menggunakan pengujian standarisasi ISO 9126, yang terdiri dari beberapa komponen yaitu dapat dilihat pada tabel 1 .

Tabel 1 Pengukuran Indikator Standarisasi ISO 9126

\begin{tabular}{|c|c|c|c|}
\hline No & Variabel & Sub-variabel & Indikator Pengukuran \\
\hline \multirow[t]{5}{*}{1} & \multirow{5}{*}{ Fungsionalitas } & Kesesuaian & Kesesuaian sistem dengan kebutuhan \\
\hline & & Ketepatan & Keakuratan informasi yang dihasilkan oleh sistem \\
\hline & & Keamanan & Keamanan data dan pengguna \\
\hline & & Interoperabitilas & $\begin{array}{l}\text { Integritas dan akses sistem dengan perbedaan } \\
\text { teknologi yang digunakan }\end{array}$ \\
\hline & & Pemenuhan & Kesesuaian sistem dengan peraturan yang berlaku \\
\hline \multirow[t]{3}{*}{2} & \multirow[t]{3}{*}{ Keandalan } & Kematangan & Rendahnya tingkat kesalahan dalam sistem \\
\hline & & Toleransi Kesalahan & $\begin{array}{l}\text { Kemampuan untuk berfungsi seperti biasa setelah } \\
\text { terjadi kesalahan }\end{array}$ \\
\hline & & Pemulihan & $\begin{array}{l}\text { Kemampuan sistem untuk mengatasi } \\
\text { kesalahan yang terjadi }\end{array}$ \\
\hline \multirow[t]{4}{*}{3} & \multirow[t]{4}{*}{ Kegunaan } & Understandibilitas & Kemudahan sistem untuk dipahami \\
\hline & & Learnabilitas & Kemudahan sistem untuk dipelajari \\
\hline & & Operabilitas & Kemudahan sistem untuk dioperasikan \\
\hline & & Ketertarikan & Kenyamanan pengguna dalam menggunakan sistem \\
\hline \multirow[t]{2}{*}{4} & \multirow[t]{2}{*}{ Efisiensi } & Prilaku Waktu & Kecepatan respon dan waktu pengolahan \\
\hline & & Prilaku Sumber Daya & Kesesuaian penggunaan sumber daya \\
\hline \multirow[t]{4}{*}{5} & \multirow[t]{4}{*}{ Perawatan } & Stabilitas & Kemampuan mengatasi efek dari modifikasi \\
\hline & & Analisabilitas & $\begin{array}{l}\text { Kemudahan untuk mengidentifikasi bagian dari } \\
\text { kesalahan }\end{array}$ \\
\hline & & Perubahan & $\begin{array}{l}\text { Menghilangkan kesalahan atau perubahan pada } \\
\text { sistem }\end{array}$ \\
\hline & & Testabilitas & Kemampuan dalam pengujian sistem \\
\hline \multirow[t]{4}{*}{6} & \multirow[t]{4}{*}{ Portabilitas } & Instalbilitas & $\begin{array}{l}\text { Kemampuan sistem dapat digunakan dalam } \\
\text { lingkungan tertentu }\end{array}$ \\
\hline & & Kesesuaian & Kesesuaian kinerja dan kualitas sistem \\
\hline & & Dapat Diganti & $\begin{array}{l}\text { Kemapuan dari sistem untuk digantikan dengan } \\
\text { sistem lain }\end{array}$ \\
\hline & & Penyesuaian & $\begin{array}{l}\text { Kemampuan dari sistem untuk beradaptasi dengan } \\
\text { lingkungan yang berbeda }\end{array}$ \\
\hline
\end{tabular}

f. Hasil

Hasil pengujian berupa aplikasi kamus bahasa ilmiah tumbuhan menggunakan metode sequential search berbasis android.

\section{Teknik Pengumpulan Data}

Pengumpulan data untuk penelitian ini menggunakan beberapa metode sebagai berikut :

1. Observasi

Pengumpulan data dengan metode observasi yaitu metode pengumpulan data dengan cara meminta data langsung mengenai nama-nama ilimiah ke Dinas Pertanian Kota Bandar Lampung. 
2. Tinjauan Pustaka (Library Research)

Proses pengumpulan data yang dilakukan dengan mempelajari berbagai bentuk bahan tertulis yang berupa buku-buku, artikel, dokumen-dokumen, termasuk laporan yang ada kaitannya secara langsung. Pada metode ini penulis mempelajari buku-buku penunjang dan dokumen yang terkait dan dapat dijadikan acuan untuk mengadakan dan menguraikan pembahasan (Darwis et al., 2019; Eka et al., 2020; Nugroho et al., 2021; Putra, 2020).

\section{HASIL DAN PEMBAHASAN}

Implementasi Sistem

Tahap implementasi merupakan tahap translasi desain yang telah dirancang ke dalam kode program, implementasi yang dilakukan meliputi implementasi rancangan antar muka (user interface) (Isnian \& Suaidah, 2016; Juniansyah et al., 2020; Kumala et al., 2020; Rusliyawati et al., 2021). Sesuai dengan rancangan storyboard yang sudah dibuat, maka hasil implementasi rancangan interface (Aldino \& Sulistiani, 2020; Sari et al., 2021; Sintaro et al., 2020).

\section{Menu Utama}

Halaman menu utama terdapat menu-menu yang dapat dipilih oleh pengguna. Halaman menu utama terdapat menu abjad a-z, kategori dan tentang. Hasil implementasi menu utama dapat dilihat pada gambar 2 sebagai berikut:

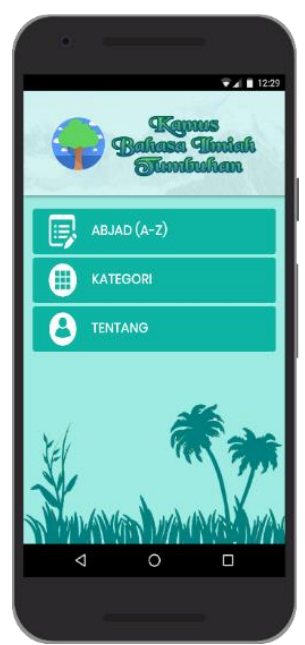

Gambar 2. Tampilan Menu Utama

\section{Menu Abjad}

Halaman abjad a-z terdapat urutan index kamus yang dapat dilihat dan dipilih oleh pengguna. Pengguna dapat mencari nama tumbuhan yang diinginkan. Hasil implementasi halaman abad a-z dapat dilihat pada gambar 3 sebagai berikut: 


\section{Menu Tumbuhan}

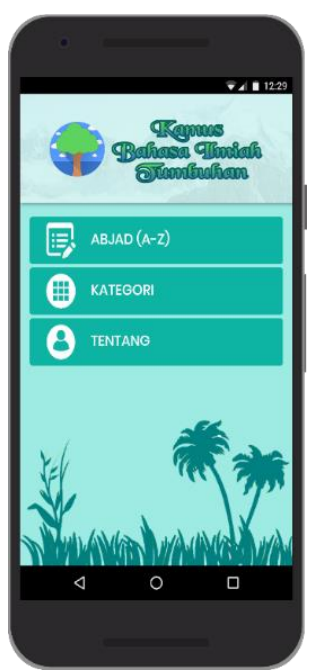

\section{Gambar 3. Tampilan Menu Abjad}

Halaman nama tumbuhan terdapat gambar tumbuhan, nama tumbuhan, nama ilmiah tumbuhan, kategori tumbuhan dan jenis tumbuhan. Pengguna dapat mengetahui gambar dari tumbuhan, nama ilmiah tumbuhan, kategori tumbuhan dan jenis tumbuhan tersebut. Hasil implementasi halaman nama tumbuhan dapat dilihat pada gambar 4 sebagai berikut:

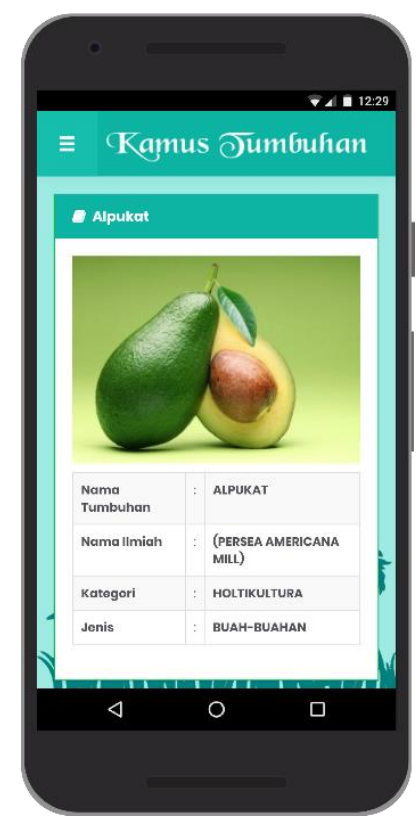

Gambar 4. Tampilan Menu Tumbuhan

\section{Menu Kategori}

Halaman menu kategori terdapat menu-menu yang bisa dipilih oleh pengguna. Halaman menu kategori terdapat menu perkebunan, tanaman pangan dan holtikultura. Hasil implementasi menu utama dapat dilihat pada gambar 5 sebagai berikut: 


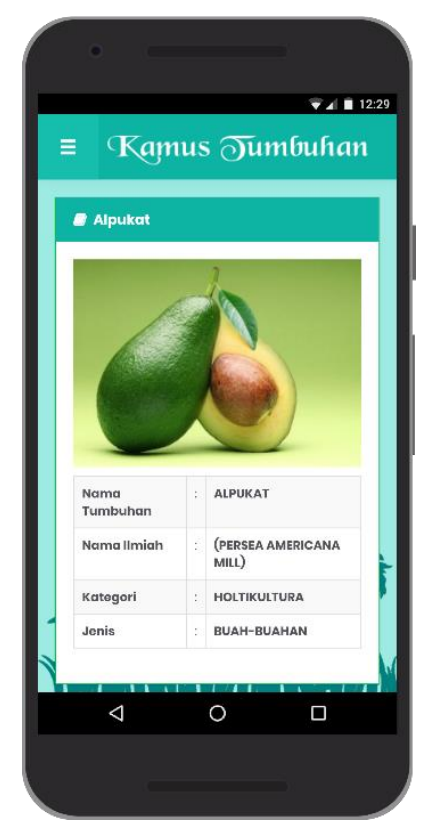

Gambar 5. Tampilan Menu Kategori

\section{SIMPULAN}

Berdasarkan hasil penelitian dan pembahasan, maka dapat disimpulkan sebagai berikut Aplikasi Kamus Bahasa Ilmiah Tumbuhan Berbasis Android ini dapat digunakan oleh siswa dan mahasiswa serta masyarakat, sebagai sarana belajar dan alternatif untuk memperluas pengetahuan pengguna dalam mengenal nama-nama ilmiah yang terdapat pada setiap tumbuhan. Aplikasi kamus ini terdapat menu abjad a-z sehingga dapat menampilkan nama-nama tumbuhan mulai dari abjad a sampai dengan abjad $\mathrm{z}$, serta dilengkapi fitur pencarian yang dapat mempermudah pengguna dalam mencari nama-nama tumbuhan. Selain itu terdapat fitur kategori mulai dari perkebunan, tanaman pangan dan holtikultura. Algoritma pencarian yang digunakan di dalam aplikasi Kamus Bahasa Ilmiah Tumbuhan ini adalah algoritma sequential search atau disebut dengan pencarian beruntun yang dapat digunakan untuk melakukan pencarian data, baik pada array yang sudah terurut maupun belum terurut. Pencarian ini dapat digunakan dengan memasukkan nama tumbuhan yang akan dicari, setelah pengguna menemukan nama tumbuhan yang dicari maka pengguna dapat melihat gambar, nama ilmiah, kategori dan jenis pada tumbuhan tersebut.

\section{REFERENSI/DAFTAR PUSTAKA}

Ahdan, S., \& Setiawansyah, S. (2020). Pengembangan Sistem Informasi Geografis Untuk Pendonor Darah Tetap di Bandar Lampung dengan Algoritma Dijkstra berbasis Android. Jurnal Sains Dan Informatika: Research of Science and Informatic, 6(2), 67-77.

Ahdan, S., \& Setiawansyah, S. (2021). Android-Based Geolocation Technology on a Blood Donation System (BDS) Using the Dijkstra Algorithm. IJAIT (International Journal of Applied Information Technology), 1-15.

Aldino, A. A., \& Sulistiani, H. (2020). DECISION TREE C4. 5 ALGORITHM FOR TUITION AID GRANT PROGRAM CLASSIFICATION (CASE STUDY: DEPARTMENT OF INFORMATION SYSTEM, UNIVERSITAS TEKNOKRAT INDONESIA). Edutic-Scientific Journal of Informatics Education, 7(1).

Darwis, D., Pasaribu, A. F., \& Surahman, A. (2019). Sistem Pencarian Lokasi Bengkel Mobil Resmi Menggunakan Teknik Pengolahan Suara dan Pemrosesan Bahasa Alami. Jurnal Teknoinfo, 13(2), 71-77.

Eka, S., Putri, Y., \& Surahman, A. (2020). PENERAPAN MODEL NAIVE BAYES UNTUK MEMPREDIKSI POTENSI PENDAFTARAN SISWA DI SMK TAMAN SISWA TELUK BETUNG BERBASIS WEB. 1(1), 93-99.

Isnian, A. R., \& Suaidah, Y. T. U. (2016). Sistem Pendukung Keputusan Penerimaan Asisten Dosen Pada Perguruan Tinggi Teknokrat Menggunakan Metode Analytical Hierarchy Process (AHP). Jupiter, 2(1).

Juniansyah, B. D., Susanto, E. R., \& Wahyudi, A. D. (2020). Pembuatan E-Commerce Pemesanan Jasa Event Organizer Untuk Zero Seven Entertaiment. Jurnal Tekno Kompak, 14(1), 41-46.

Kumala, N. K. R., Puspaningrum, A. S., \& Setiawansyah, S. (2020). E-DELIVERY MAKANAN BERBASIS MOBILE (STUDI KASUS: OKONOMIX KEDATON BANDAR LAMPUNG). Jurnal Teknologi Dan Sistem Informasi, 1(2), $105-110$.

Kurniawan, I., Setiawansyah, \& Nuralia. (2020). PEMANFAATAN TEKNOLOGI AUGMENTED REALITY UNTUK 405 
PENGENALAN PAHLAWAN INDONESIA DENGAN MAR KER. Jurnal Informatika Dan Rekayasa Perangkat Lunak, 1(1), 9-16.

Megawaty, D. A., Damayanti, D., Assubhi, Z. S., \& Assuja, M. A. (2021). APLIKASI PERMAINAN SEB AGAI MEDIA PEMBELAJARAN PETA DAN BUDAYA SUMATERA UNTUK SISWA SEKOLAH DASAR. Jurnal Komputasi, 9(1), 58-66.

Nugroho, N., Rahmanto, Y., Rusliyawati, R., Alita, D., \& Handika, H. (2021). Software Development Sistem Informasi Kursus Mengemudi (Kasus: Kursus Mengemudi Widi Mandiri). J-SAKTI (Jurnal Sains Komputer Dan Informatika), 5(1), 328-336.

Nurmanto, D., \& Gunawan, R. D. (2020). PEMANFAATAN AUGMENTED REALITY DALAM APLIKASI MAGIC BOOK PENGENALAN PROFESI UNTUK PENDIDIKAN ANAK USIA DINI. 1(1), 36-42.

Putra, A. D. (2020). RANCANG BANGUN APLIKASI E-COMMERCE UNTUK USAHA PENJUALAN HELM. Jurnal Informatika Dan Rekayasa Perangkat Lunak, 1(1), 17-24.

Rahmanto, Y., Alfian, J., Damayanti, D., \& Borman, R. I. (2021). Penerapan Algoritma Sequential Search pada Aplikasi Kamus Bahasa Ilmiah Tumbuhan.

Rusliyawati, R., Putri, T. M., \& Darwis, D. (2021). Penerapan Metode Garis Lurus dalam Sistem Informasi Akuntansi Perhitungan Penyusutan Aktiva Tetap pada PO Puspa Jaya. Jurnal Ilmiah Sistem Informasi Akuntansi, 1(1), 1-13.

Sari, M. P., Setiawansyah, S., \& Budiman, A. (2021). PERANCANGAN SISTEM INFORMASI MANAJEMEN PERPUSTAKAAN MENGGUNAKAN METODE FAST (FRAMEWORK FOR THE APPLICATION SYSTEM THINKING)(STUDI KASUS: SMAN 1 NEGERI KATON). Jurnal Teknologi Dan Sistem Informasi, 2(2), 69-77.

Setiawansyah, S., Adrian, Q. J., \& Devija, R. N. (2021). Penerapan Sistem Informasi Administrasi Perpustakaan Menggunakan Model Desain User Experience. Jurnal Manajemen Informatika (JAMIKA), 11(1), 24-36.

Shodik, N., Neneng, N., \& Ahmad, I. (2019). Sistem Rekomendasi Pemilihan Smartphone Snapdragon 636 Menggunakan Metode Simple Multi Attribute Rating Technique (Smart). Jurnal Nasional Pendidikan Teknik Informatika (JANAPATI), 7(3), 219. https://doi.org/10.23887/janapati.v7i3.15727

Sintaro, S., Surahman, A., \& Khairandi, N. (2020). APLIKASI PEMBELAJARAN TEKNIK DASAR FUTSAL MENGGUNAKAN AUGMENTED REALITY BERBASIS ANDROID. TELEFORTECH: Journal of Telematics and Information Technology, 1(1), 22-31.

Sulistiani, H., Yuliani, A., \& Hamidy, F. (2021). Perancangan Sistem Informasi Akuntansi Upah Lembur Karyawan Menggunakan Extreme Programming. Technomedia Journal, 6(01 Agustus). 